\title{
ANÁLISE DOS CONTAMINANTES PRESENTES NA AREIA DE FUNDIÇÃO*
}

\author{
Viviane Sardilli Rodrigues ${ }^{1}$ \\ Bruno Karolski \\ Denise Crocce Espinosa Romano 3 \\ Jorge Alberto Soares Tenório 4
}

\section{Resumo}

Areia de fundição é utilizada para modelar peças metálicas no setor metalúrgico. Existem vários tipos de areia usadas para essa finalidade que em sua composição possuem desde o quartzo até a areia de zircônio, nas quais o uso de cada uma é dependente da temperatura e do material que será fundido. Um tipo de areia especificamente, a areia de cromita, é utilizada para fabricações de peças feitas a base de aço. Para aglomerar os grãos e construir moldes onde o metal líquido é derramado usa - se resina sintética, comumente a resina fenólica, que é produzida através da reação da reação química entre o fenol e o formaldeído (formol) empregando catalisadores ácidos ou ésteres. A estrutura presente nas resinas são ainda de longe compreendidas. Por se tratar de uma química complexa, poucos estudos são encontrados sobre as alterações na composição após a pirólise e o comportamento da resina perante ao material refratário. Neste trabalho o objetivo foi a identificação dos contaminantes residuais presentes na areia após o processo de fundição, além da caracterização dos metais também existentes no material. Através deste estudo pretendemos identificar os potenciais contaminantes ambientais presentes na areia de fundição para avaliar um possível tratamento através de biorremediação por micro-organismos.

Palavras-chave: Areia de fundição; Cromita; Resina fenólica

\section{ANALYSIS OF POLLUTANTS PRESENT IN THE FOUNDRY SAND \\ Abstract}

Foundry sand is used in manufacture metal parts. There are many types of sand on metallurgical sector from quartz to zirconium sand. The choice of different types depend on the temperature and the material that will be melted. In this paper, we treat the sand of chromite, applied in fabrications of parts made of steel. Synthetic resin, commonly phenolic resin, is used to agglomerate the grains. The resin is produced by chemical reaction between phenol and formaldehyde, applying acid catalysts or esters. The structure present in the resins is still poorly understood, because it is a complex chemistry. Therefore, few studies have been found on the changes in the composition after the pyrolysis and the behavior of the resin in front of the refractory material. In this work, the objective is the identification of the contaminants present in the sand coming from the phenolic resin after the casting process, besides the characterization of the metals also present in the substrate. This characterization, in addition to contribute in the understanding of the foundry sand contamination potential, will be very helpful in a bioremediation treatment evaluating, our final objective.

Keywords: Foundry sand; Chromite; Phenolic resin

1 Engenheira Química, mestranda, Departamento de Engenharia Química, Escola Politécnica da Universidade de São Paulo, São Paulo, SP, Brasil. 
2 Biólogo, doutor, pesquisador, Centro de Pesquisa em Meio Ambiente - CEPEMA, Escola Politécnica da Universidade de São Paulo, Cubatão, SP, Brasil.

3 Engenheira Metalurgista, doutora, professora associada, Departamento de Engenharia Química, Escola Politécnica da Universidade de São Paulo, São Paulo, Brasil.

4 Engenheiro Metalurgista, doutor, professor titular, Departamento de Engenharia Química, Escola Politécnica da Universidade de São Paulo, São Paulo, SP, Brasil. 


\section{INTRODUÇÃO}

$\mathrm{Na}$ indústria metalúrgica o rejeito mais descartado em aterros industriais é a areia de fundição, chamada também de areia de moldagem. Emprega - se mais esse material nos processos de fundição, devido a suas virtudes, como: ter mais resistência a danos por calor, ser mais disponível, apresentar baixo custo e possuir afinidades com ligantes de material orgânico. O principal motivo do despejo é que quando ela é usada por muitas vezes a sua capacidade de resistência ao fogo é perdida, levando a perda de sua função ao processo de moldagem (1).

Em processos que necessitam temperaturas elevadas, acima de $3000^{\circ} \mathrm{C}$, utilizam areias com pontos de fusão mais elevados do que quartzo. Entre essas matérias - primas estão o silicato de zircônio, a areia de cromita e a areia de olivina (2).

A areia de cromita é uma areia não silicosa, por não conter a sílica em sua fórmula química e, é sintetizada através da fragmentação das rochas de cromita e ferro $\left(\mathrm{FeO} . \mathrm{Cr}_{2} \mathrm{O}_{3}\right)$, porém há a presença de $\mathrm{SiO}_{2}$ que é considerada pela indústria uma impureza (3).

Esse material tem boa capacidade à penetração de metais, alta condutividade térmica e densidade específica, promovendo um resfriamento uniforme e acentuado, empregado geralmente em situações que não podem ocorrer defeitos em peças por expansão $(2,3,4)$.

As areias de moldagens são normalmente aglomeradas com o auxílio de resinas sintéticas, usualmente são as termofixas que tem como a principal característica suportar temperaturas a partir de $2000^{\circ} \mathrm{C}$. Além de aglutinar os grãos de areia, as suas outras habilidades são de ter uma estabilidade térmica e mecânica, uma boa resistência a perda de fogo e um ótimo isolante térmico e elétrico (5). São compostos classificados como termofixos, e possuem a capacidade de polimerização ou de cura em temperaturas elevadas (acima de $130^{\circ} \mathrm{C}$ ), em outras palavras, as moléculas se fundem formando polímeros de alta densidade de ligações cruzadas. O tipo de ligação química favorece a ductibilidade da resina, formando uma matéria sólida e quimicamente inerte. A iniciação da reação de polimerização geralmente é induzida por catalisadores como ácidos e ésteres, ou por indução física, como o calor ou radiação $(3,6)$. Ao se solidificarem formam - se materiais insolúveis, infusíveis, estáveis e de alta rigidez, como mencionada acima. Isso acontece por reações químicas complexas, como reticularão das moléculas, polimerização e até condensação $(3,7)$.

Porém, as areias quimicamente ligadas, principalmente as resinas fenólica, furânica e alquímica apresentam um teor de toxidez considerado elevado pela legislação (8).

As resinas fenólicas são produzidas pela reação entre o formol e o fenol. Quando há excesso de formaldeído ou quando são equimolares a resina se caracteriza básica recebendo o nome de resol. Já quando o fenol está em maior quantidade em relação ao formol, a caracterização desse copolímero é ácida, nomeando - o de novolaca. A escolha entre essas duas resinas dependerá do processo empregado. Para a sintetização ocorrer é necessário o uso de aditivos que catalisam a reação, podendo ser ácidos orgânicos ou inorgânicos para as resinas ácidas e para as resinas básicas são utilizados catalisadores básicos, como os hidróxidos de sódio, potássio ou de bário $(5,6)$.

Segundo a ABNT, a areia de fundição não é um rejeito perigoso, mas isso não é o suficiente em considera - lá como um descarte não nocivo ao ambiente, 
pois isso dependerá das características do metal fundido e do ligante aplicado no processo. Devido a esses fatores, é de extrema relevância identificar a composição química presente antes de tomar qualquer decisão de descarte (9). E quando se trata de fenol a atenção aumenta, já que o fenol é um solvente orgânico altamente tóxico que oferece riscos ao meio ambiente e aos seres humanos (5). Além dos contaminantes orgânicos há a presença de metais, como o Cromo, o Ferro e evidências de Alumínio, que se tornam tóxicos quando presentes ao ecossistema.

O objetivo deste trabalho é a caracterização das substâncias presentes, na areia de fundição, principalmente após a pirólise, focando substâncias orgânicas e inorgânicas, com potencial de contaminação ambiental. Poucos estudos na literatura são encontrados a respeito do que ocorre com a resina após a queima, e se a areia após sua utilização possui um potencial de contaminação do ambiente. Essa informação é de extrema importância uma vez que existem pesquisas voltadas a reciclagem desse resíduo no setor da construção civil $(10,11)$, o que aumenta significativamente o contato com esse rejeito industrial.

\section{MATERIAIS E MÉTODOS}

\subsection{Extração}

Para análise da presença de substâncias orgânicas aromáticas na areia de fundição, foi realizada uma extração misturando - se metanol $(60 \mathrm{~mL})$ junto a areia de fundição (100 gramas), tanto a areia já utilizada (queimada) quanto a areia ainda não utilizada (não queimada). O metanol foi acrescentado até que cobrisse todo o volume de areia. Essa mistura foi agitada em frasco aberto com o auxílio de um agitador magnético (IKA® C - MAG HS 4) por 5 dias. Toda a vez que se observou que o volume de metanol havia baixado, este volume foi completado com metanol até que toda a areia fosse coberta novamente sendo este procedimento foi repetido por 3 dias. Foram retiradas alíquotas (T1, T2, T3 e T4 no $1^{\circ}$ dia, T5 e T6 no $2^{\circ}$ dia, T7 no $3^{\circ}$ dia, T8 no $4^{\circ}$ dia e T9 no 5 dia) para análises de substâncias orgânicas e suas respectivas concentrações.

\subsection{Identificação de contaminantes por HPLC}

As identificações das substâncias aromáticas orgânicas provenientes da extração por metanol das areias de fundição foram realizadas por Cromatografia Líquida de Alto Desempenho (HPLC, sigla em inglês). Para isso, uma alíquota da extração (1 $\mathrm{mL}$ ) foi filtrada em filtros de seringa PTFE de malha 0,22 $\mu \mathrm{m}$ (Millipore) e submetidas ao sistema de HPLC (Shimadzu SPD-20A) com detecção UV-VIS em $254 \mathrm{~nm}$ em uma coluna de fase reversa (C 18 ACE 121-2546, 250 x 4,6 mm) tendo como fase móvel um gradiente acetonitrila e água a um fluxo de 0,8 $\mathrm{mL}$ por minuto. O gradiente utilizado foi $22 \%$ acetonitrila ( 0 a 3 minutos); $50 \%$ acetonitrila ( 3 a 5 minutos e de 5 a 10 minutos); e 22\% de acetonitrila (10 a 12 minutos e 12 a 14 minutos). Como curva de quantificação foi utilizada uma mistura de fenol (1000 ppm), meta-cresol (400 ppm) e orto-cresol (200 ppm) e diluições de 1:100; 1:50; $1: 20 ; 1: 10$ e $1: 1$ e a solução $100 \%$. 


\subsection{Caracterização de metais}

Para a caracterização dos metais presentes no substrato foi adotado o método baseado na EPA $3051 \mathrm{~A}$ para sólos. Para tanto, as amostras foram submetidas a uma digestão ácida, utilizando-se $100 \mathrm{~L}$ de amostra, $1 \mathrm{~mL}$ de $\mathrm{HNO}_{3} \mathrm{e}$ o volume completado para $5 \mathrm{~mL}$ de água deionizada. A mistura foi submetida ao forno de micro-ondas por 20 minutos de aquecimento em $90 \stackrel{\circ}{ } \mathrm{C}$. Após o resfriamento do material $5 \mathrm{~mL}$ de água deionizada foram adicionados à mistura para auxiliar na solubilização dos metais. A amostra então foi analisada em ICP - OES (Varian 710 ES).

\section{RESULTADOS E DISCUSSÃO}

\subsection{Análise de contaminantes na areia de fundição}

Pelo método de extração utilizado, conseguimos identificar 3 substâncias orgânicas nas areias de fundição estudadas: fenol (pico A, Figuras 1 e 2), metacresol (pico B, Figuras 1 e 2) e orto - cresol (pico C, Figuras 1 e 2) pois tiveram os mesmos tempos de retenção pelo HPLC que a curva padrão utilizada. Sendo a resina baseada em fenol e formaldeído, conseguimos observar, através do método de extração utilizado, que mesmo após a utilização, o fenol continua presente na areia (2651 ppm) em concentrações próximas à areia que ainda não foi utilizada (2531 ppm). Os valores obtidos até então são valores preliminares uma vez que a curva de quantificação realizada não está adequada para as concentrações observadas. Nossa expectativa era que para a massa de areia utilizada, a concentração dos hidrocarbonetos analisados estaria dentro da faixa da curva de quantificação, o que não aconteceu. As análises revelaram uma concentração muito maior do que o esperado e o que podemos já afirmar, é que a areia após seu uso possui uma concentração de fenol tão alta quanto a encontrada antes de seu uso. Essas concentrações encontradas justifica o armazenamento adequado da areia de fundição após seu uso pelo seu grande potencial de contaminação ambiental.

Com relação ao meta-cresol e orto-cresol, estas substâncias se assemelham muito ao fenol, a diferença é um grupo metil ligado ao carbono 2 (orto) e ao 3 (meta). Apesar de não ser utilizado nenhum desses hidrocarbonetos na composição da resina, eles podem ser formados pela reação fenol e formol na produção desta. Pelo observado, esses dois hidrocarbonetos são de certa forma afetados pelo uso da areia uma vez que as concentrações encontradas na areia não queimada são maiores do que as encontradas na areia queimada (Tabela 1). Essa diferença de concentração encontrada pode ser causada pela degradação do meta e orto-cresol pelo calor no uso da areia explicando a diferença encontrada. Esses dois hidrocarbonetos em especial são considerados ainda mais problemáticos do que 0 fenol, pois sua toxicidade para seres vivos é ainda maior (5).

A concentração encontrada na areia de fundição está muito acima do permitido para descarte (9) o que adiciona um grau ainda maior de cuidado em seu armazenamento e descarte. 


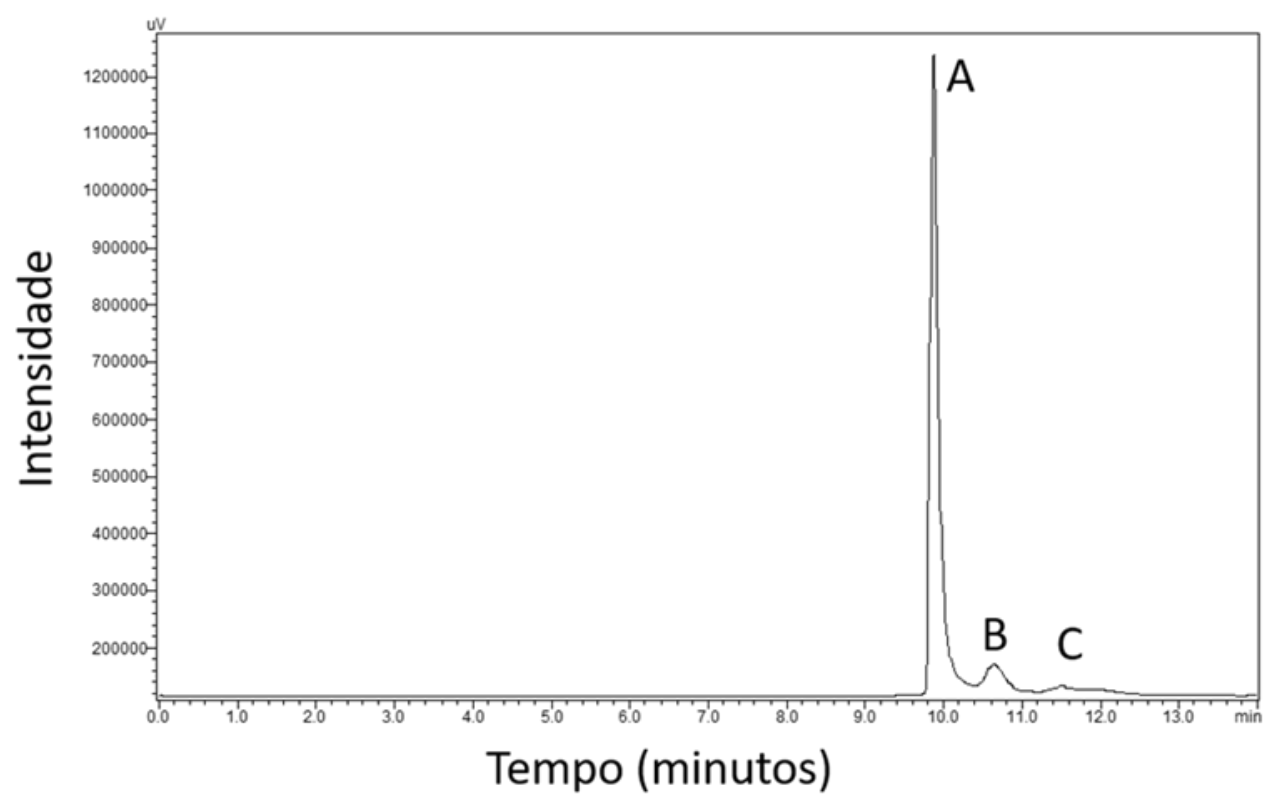

Figura 1: Gráfico representativo da determinação dos contaminantes presentes na areia de fundição antes do uso

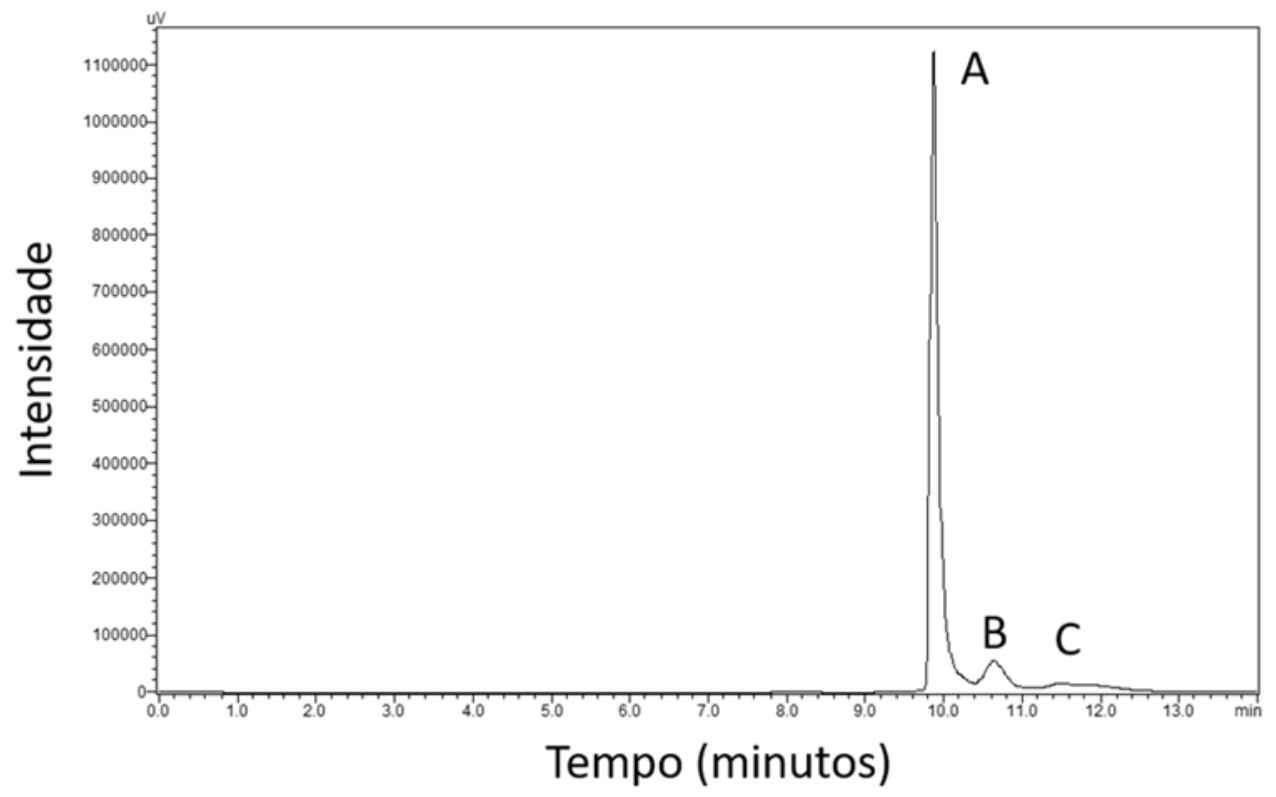

Figura 2: Gráfico representativo da determinação dos contaminantes presentes na areia de fundição depois do uso

Tabela 1: Concentração dos contaminantes identificados na areia de fundição antes e depois do uso

\begin{tabular}{|c|c|c|}
\hline Contaminante & \multicolumn{2}{|c|}{ Concentração (ppm) } \\
\hline & Areia não queimada & Areia queimada \\
\hline Fenol & 2431,7152 & 2656,1656 \\
\hline Meta - cresol & 925,8606 & 602,0685 \\
\hline Orto - cresol & 690,8536 & 161,6555 \\
\hline
\end{tabular}




\subsection{Análise da presença de metais}

Levando - se em consideração que a areia de fundição é utilizada como molde para peças metálicas, a areia foi testada quanto a concentrações de metal presentes antes e após sua utilização nos moldes. Nossas análises revelaram a presença de alguns metais sendo o ferro, o alumínio e o cromo os mais presentes (Tabela 2). Os metais alumínio e cromo são metais tóxicos já bem descritos na literatura $(12,13)$ e que são encontrados antes e depois da utilização da areia em questão. As concentrações encontradas desses metais, apesar de baixas, podem afetar o meio ambiente levando - se em consideração a massa total da areia utilizada e armazenada que é na ordem de toneladas. Nessa ordem de grandeza, as concentrações achadas de metal passam a ser preocupantes adicionando ainda mais um agravante nesse rejeito industrial, porém, a concentração dos resíduos de hidrocarbonetos aromáticos é de longe a parte mais problemática deste resíduo.

Tabela 2: Concentração dos principais metais encontrados na areia de fundição antes e depois do uso

\begin{tabular}{|c|c|c|c|}
\hline & Al (ppm) & Fe (ppm) & Cr (ppm) \\
\hline $\begin{array}{c}\text { Areia não } \\
\text { queimada }\end{array}$ & 0,4694 & 2,46854 & 0,090212 \\
\hline Areia queimada & 0,16120 & 3,21724 & 0,09146 \\
\hline
\end{tabular}

\section{CONCLUSÃO}

Os métodos apresentados nesse trabalho deixam claro que há contaminantes derivados do fenol na areia de fundição, inclusive após a pirólise, que é quando é destinada aos aterros industriais. Além do próprio fenol, matéria prima da resina fenólica, ainda foram encontrados meta - cresol e orto - cresol, dois contaminantes conhecidamente tóxicos e com grande potencial de contaminação ambiental. Apesar da areia ser utilizada para moldagem de ligas metálicas, a concentração de metais contribui para o rejeito tenha maior potencial de contaminação do meio ambiente.

Essa caracterização da areia de fundição é primeiro passo para o objetivo final do trabalho que é a avaliação e tentativa de tratamento desse importante resíduo através da biorremediação. Esta técnica vem sendo cada vez mais empregada em rejeitos industriais para eliminar contaminantes que possam afetar 0 meio ambiente diminuindo sua periculosidade, e, no caso da areia de fundição, com possibilidade até de reuso no processo.

\section{Agradecimentos}

Os autores agradecem à Coordenação de Aperfeiçoamento de Pessoal de Nível Superior (Capes), ao Conselho Nacional de Desenvolvimento Científico e Tecnológico (CNPq) e à Fundação de Amparo à Pesquisa do Estado de São Paulo (Fapesp) processo no 2012/51871 - 9 e no 2014/13351 - 9). 


\section{REFERÊNCIAS}

1. Singh G, Siddique R. Effect of waste foundry sand (WFS) as partial replacement of sand on the strength, ultrasonic pulse velocity and permeability of concrete.

BuildMater[Internet]. 2011;26(1):7. Disponível em:

http://linkinghub.elsevier.com/retrieve/pii/S0950061811003047

2. BERNDT H. A tecnologia do Processo Shell. 1989. 260 p.

3. QUÍMICA A. Resinas sintéticas. 1989.150 p.

4. Katz S., Landefeld GF. Foundry Processes - Their Chemistry and Physics. Londres: General Motors Research Laboratories Warren, Michigan; 1988

5. Gardziella A., Pilato LA., Knop A. Phenolic Resins: Chemistry, Applications, Standardization, Safety and Ecology [Internet]. 2000. 560 p. Disponível em: http://books.google.com.ar/books/about/Phenolic_Resins.html?id=CDOAraoWwTMC\&p gis $=1$

6. Bitencourt CS, Pandolfelli VC. Resinas termofixas e a produção de refratários contendo carbono: base teórica e insights para futuros desenvolvimentos. Cerâmica. 2013;59:126.

7. M. Chanda SKR. Industrial polymers, specialty polymers, and their applications. 1a Ed. Ed. CRCEd. CRC, editor. Boca Raton, EU; 2008.

8. Soares WÂA, Ferraresi GN, Quináglia GA, Umbuzeiro GDA. Toxicidade do resíduo areia de fundição utilizando o teste com a bactéria luminescente Vibrio fischeri. Rev Bras Toxicol. 2010;23(1-2):17-21.

9. ABNT. NBR 10.004 - Resíduos sólidos - Classificação [Internet]. Vol. 18. Rio de Janeiro; 2004. Disponível em: https://www.mendeley.com/research/classifica??ores?duos-s?lidos-industriais-com-base-em-testes-ecotoxicol?gicos-utilizando-daphniama/\%5Cnhttps://www.journal.ufsc.br/index.php/biotemas/article/view/21407

10. Dungan RS, Kukier U, Lee B. Blending foundry sands with soil: Effect on dehydrogenase activity. Sci Total Environ. 2006;357(1-3):221-30.

11. Siddique R, Schutter G de, Noumowe A. Effect of used-foundry sand on the mechanical properties of concrete. Constr Build Mater [Internet]. 2009;23(2):976-80. Disponível em: http://dx.doi.org/10.1016/j.conbuildmat.2008.05.005

12. Gensemer RW, Playle RC. The Bioavailability and Toxicity of Aluminum in Aquatic Environments. Crit Rev Environ Sci Technol [Internet]. 1999;29(4):315-450. Disponível em: http://www.tandfonline.com/doi/abs/10.1080/10643389991259245

13. Panda RC, Selvasekhar S, Murugan D, Sivakumar V, Narayani T, Sreepradha C. Cleaner production of basic chromium sulfate - With a review of sustainable green production options. Vol. 112, Journal of Cleaner Production. 2016. p. 4854-62. 